\title{
The anxiety disorder spectrum:
}

\author{
Fear imagery, physiological reactivity, and differential diagnosis \\ Peter J. Lang, Ph.D.* and Lisa M. McTeague, Ph.D.* \\ *University of Florida
}

\begin{abstract}
This review considers recent research assessing psychophysiological reactivity to fear imagery in anxiety disorder patients. As in animal subjects, fear cues prompt in humans a state of defensive motivation in which autonomic and somatic survival reflexes are markedly enhanced. Thus, a startle stimulus presented in a fear context yields a stronger (potentiated) reflex, providing a quantitative measure of fearful arousal. This fear potentiation is further exaggerated in specific or social phobia individuals when viewing pictures or imagining the phobic object. Paradoxically, fear imagery studies with more severe anxiety disorder patients - panic disorder with agoraphobia, generalized anxiety disorder, or anxious patients with comorbid depression — show a blunted, less robust fear potentiated response. Furthermore, this reflex blunting appears to systematically be more pronounced over the anxiety disorder spectrum, coincident with lengthier chronicity, worsening clinician-based judgments of severity and prognosis, and increased questionnaire-based indices of negative affectivity, suggesting that normal defensive reactivity may be compromised by an experience of long-term stress.
\end{abstract}

\section{Keywords}

mental imagery; fear; anxiety; social anxiety; phobia; GAD; panic; agoraphobia; startle; psychophysiology; comorbidity; depression; emotional reactivity; narrative imagery

Diagnosis of anxiety is generally accomplished wholly by interview (e.g., DSM-IV, APA, 1994). Questionnaires are sometimes additionally administered and a physical examination may be ordered to determine that no other medical condition or disability is present. However, supplementary, quantitative tests of anxious behavior or physiology are rarely sought. Thus, although observations of the demeanor of the interviewee are certainly considered in forming a diagnosis, the primary data come from the patient's verbal responses to the diagnostician's careful questioning.

Despite the emphasis on verbal report in diagnosis, most theories of anxiety disorder (e.g., Barlow, 2002; Reiss, 1991) presume that the reports of fear and anxiety reflect an underlying distressing state of physiological hyperarousal. The aim of this paper is to consider whether anxious patients reporting fearful thoughts and images actually evidence associated patterns of physiological arousal, whether differences in arousal patterns covary with diagnostic distinctions as defined by DSM-IV, and to consider the possibility that the physiology of fear might support alternative organizations of anxiety disorder symptomology (i.e., that physiological reactivity over the anxiety disorder spectrum covaries meaningfully with a dimension of increasing negative affectivity).

Corresponding author: Peter J. Lang, PhD, Center for the Study of Emotion \& Attention University of Florida, PO Box 112766, Gainesville, FL 32611, email: plang @ phhp.ufl.edu, Telephone: (352) 392-2439, Fax: (352) 392-6047. 


\section{Fear, Startle, and the Mammalian Defense System}

The theoretical view taken here assumes that emotions reflect the activation of two motive circuits in the brain that evolved because they promoted the survival of individuals and their genetic progeny: An appetitive motive system associated with approach to nutrients, sexual behavior, care of offspring, and a defensive motive system that responds to environmental threat. Both systems involve reflex reactions, autonomic and somatic, that are widely shared by most mammals and that are activated in humans during states of pleasant or unpleasant emotion (Lang, 1994).

At clinical interview, anxiety disordered patients all report heightened fearfulness, relative to healthy normal participants. In this paper, fear is conceived to be an action disposition (Frijda, 1987; Lang, \& Bradley, 2008) associated with efforts to escape or avoid danger and pain. These responses are deployed in the context of external threat (as are also counter-attack and other mechanisms of defense). Following Konorski (1967) and many other theorists, it is presumed that fear reactions to threat are mediated by the defense system. Furthermore, it is held that, in humans, activation of this system accompanies the most reliable reports of fear experience.

Our understanding of the brain's defense circuitry comes primarily from neuroscience research with animals-mainly rodents—using relatively simple, classical conditioning procedures. In this work, a nociceptive event (e.g., electric shock) is paired with a previously innocuous light or tone over repeated trials, until a connection is formed, such that the animal displays defensive reactions whenever the light or tone appears alone. Employing various neurosurgical, pharmacological, and electrophysiological tools, the links in the neural circuit are traced in the brain, starting from the sensory system, proceeding through the necessary connecting structures, and ending with the autonomic and motoric effector outputs. This research has repeatedly highlighted the amygdala as the center of a defense system mediating the acquisition and orchestrating the expression of conditioned "fear" (Davis, 2000; Gloor, 1960; Gray, 1989; Kapp, Pascoe, \& Bixler 1984; LeDoux, 2003).

Activation of the defense circuit begins when the lateral and basolateral nuclei of the amygdala receive threat-relevant information from any sensory system (Figure 1). These nuclei project to the amygdala's central nucleus and the bed nucleus of the stria terminalis, which in turn project to a variety of hypo-thalamic sites, the central gray, facial motor nucleus, and brainstem target areas, initiating a range of defensive reactions that counter threats to survival (Davis, 2000). Furthermore, re-entrant projections from the amygdala also feed back to sensory systems, facilitating attention and perceptual processing in the context of threat (Amaral et al., 1992).

This same neural circuitry is seen to be active in humans during emotional processing (e.g., Lang \& Davis, 2006), modulating similar autonomic responses (e.g. heart rate, skin conductance), facial muscle action, startle potentiation, and electrophysiological and hemodynamic measures of brain function. Thus, at the level of human perception, recall and recognition, it is proposed that emotion memory networks are defined by their connections to primitive motivational circuitry - appetitive, as well as defensive (Lang, 1994). Viewed from this perspective, the fear state is defined by defense system activation and its reflexive autonomic and somatic output (whether driven by external threat or internal association).

\section{The Startle Reflex: Fear and Defense}

The obligatory startle reflex may be elicited by any abrupt sensory stimulus, and serves as a primitive escape response in many species. Led by Michael Davis (e.g., Davis, 2000; Davis \& Lang, 2003) there has been extensive study of the fear conditioning paradigm and its effect on the startle reflex. In this procedure, a startle probe (a brief, abrupt acoustic stimulus) is presented 
during or shortly after the fear-conditioned cue, and the amplitude of the whole body reflex is measured through a stability-meter under the floor of the cage. As indicated in Figure 1, the increment in startle observed under these shock-threat conditions depends on the activation of the central nucleus of the amygdala and its direct projections to the pontine center (i.e., the nucleus reticularis pontis caudalis) of the normal startle reflex circuit. In this sense, the startle reflex provides a metric for the assessment of defense system activation, and indirectly, the intensity of fear.

Affective modulation of the startle reflex in humans-Neuroscience research suggests that the same mammalian defense circuitry is active in human brain (Lang \& Davis, 2006), encouraging use of the startle reflex to probe the emotional state of normal participants and patients. It has been demonstrated, first, that reactions to the conditioned shock-fear paradigm are comparable to those found with animals. That is, during extinction, startle probe responses are greater in magnitude (potentiated) when presented during fear conditioned stimuli than during control stimuli or during the inter-trial interval (e.g., Hamm, Greenwald, Bradley, \& Lang, 1993). It has also been shown that probe stimuli yield potentiated reflexes without conditioning, when participants are only instructed that shocks may be received (e.g., Bradley Moulder, \& Lang, 2005; Grillon, Ameli, Woods, Merikangas, \& Davis, 1991). Furthermore, participants reliably show augmented probe reflex responses when they look at pictures of unpleasant objects or events (Bradley, Codispoti, Cuthbert, \& Lang, 2001; Bradley, Codispoti, Sabatinelli, \& Lang, 2001) and when they imagine fearful scenarios (Vrana \& Lang, 1990; Cuthbert et al., 2003). Finally, it is clear that participants with phobia show significantly greater startle probe reflex potentation than non-fearful participants looking at pictures of phobic objects (Hamm, Cuthbert, Globisch, \& Vaitl, 1997; Sabatinelli, Bradley, \& Lang, 2001).

As would be expected, the fear stimuli that prompt potentiated probe reflexes also directly instigate changes in heart rate, increases in sweat gland activity, negative facial muscle reactions, and other measures mediated by the defense circuit (e.g., Bradley, Codispoti, Cuthbert, \& Lang, 2001). Furthermore, this same circuit, directly manipulated in the animal research, is also implicated in brain imaging studies, as shown, for example, by the close correlation between amygdala activation and activation of visual cortical areas when phobic individuals view pictures of their feared stimuli (e.g., Sabatinelli, Bradley, Fitzsimmons, \& Lang, 2005).

\section{Fearful thoughts and images: Activating the defense system}

When humans are told to imagine participating in some action, there is a sub-overt activation of the same muscles that would be the motors of the actual behavior. Similarly, when participants hear text describing fearful situations, they react with a reflex physiology of defense-increases in heart rate, skin conductance, facial muscle action, and in the magnitude of the reflexive blink response to an acoustic startle probe - matching the pattern evoked by actual fearful events (e.g., Cuthbert et al., 2003; Lang, Levin, Miller, \& Kozak, 1983; Miller et al., 1987; Vrana \& Lang, 1990; Weerts \& Lang, 1978).

It has been proposed (Bio-informational Theory: Lang, 1977; 1979; 1985) that emotional images are episodes encoded in memory as associative networks of information units. A network includes stimulus representations (cues that can be perceived), response representations (behavior, physiology, and expressive language that occur in the stimulus context), and meaning representations (associated semantic information "about" the context). It is presumed that these networks have a neural substrate, and that for emotional imagery, the response component includes activation of motivational systems (appetitive or aversive) and their reflex physiology (Lang, 1994). 
Sensory cues-pictures, text, or other media — can prompt retrieval of an emotional episode in most individuals. For example, a sentence, "The large snake darts forward, fangs protruding, striking my leg in a flash of pain", readily prompts a brief unpleasant image. In this case, verbal cues activate a network of representations that prompt a transient psychophysiological change. However, if the same verbal cues are presented to a highly fearful individual, whose snake memory network has high associative strength, we observe a more forceful responsesomatically, autonomically_in an elaborated reflex-physiology of defense (e.g., Miller et al., 1987).

\section{Imagery and Anxiety Pathology}

Almost by definition, all anxious patients are plagued by unpleasant, fearful thoughts and images and concerns about physiological symptoms. They invariably report persistent fear reactions that include pounding heart, palpitations, exaggerated startle, breathing irregularities, sweaty palms and tense muscles. Nevertheless, as stated previously it is also true that these complaints are rarely accompanied by measurement of the described physiological reactions. Curiously, when psychophysiological studies have been conducted, many anxiety patients were found to be hypo-reactive, not hyper-reactive to fearful cues (e.g., Hoehn-Saric, McLeod, Funderbunk, \& Kowalski, 2004).

Summarizing an initial series of imagery studies, we noted that, although nearly all anxiety patients report comparable fearfulness and symptoms of anxious arousal, not all anxiety diagnoses showed an accompanying physiology of defense (Lang, 1985). While defensive reactions were strong in specific phobia patients when imagining encounters with the phobic object, this was not always true for other diagnoses, most notably agoraphobia. Basing our interpretation on the bio-informational theory of emotion, we proposed that fearfulnessdefined as exaggerated defense reactions to specific cues in the environment-varies across a diagnostic spectrum, as noted at the outset. In this view, specific phobia patients are held to be the most reactive. This responsiveness was ascribed to the high associative strength (coherence) of the mediating memory networks in the brain, particularly the strong association between neural representations of the cue stimulus (with associated semantic elaborations) and the neural representations that mediate physiological arousal and action.

For panic disorder and generalized anxiety disorder, in contrast, representations of fear cues were hypothesized to be embedded in networks of low associative strength and the activation of defensive reflexes less reliably related to specific external stimuli or their internal representations. In effect, patients categorized by these diagnoses report persistent apprehension and distress, but paradoxically, from the perspective of physiological measurement, they appear to be less fearful. This conception has been supported by a series of imagery studies with anxiety patients and fearful volunteers (e.g., Lang et al., 1983; Cook, Melamed, Cuthbert, McNeil, \& Lang, 1988; McNeil, Vrana, Melamed, Cuthbert, \& Lang, 1993).

More recently, Cuthbert et al. (2003) studied emotional imagery in over 100 anxiety patients, assessing blink magnitude to a startle probe administered during imagery. As shown in Figure 2 healthy controls, specific and social phobia patients all showed significant reflex potentiation to startle probes elicited during imagery of fearful situations, indicative of heightened defensive reactivity; in contrast, patients with panic disorder with agoraphobia failed to show reliable fear-potentiation to such scenes. Previously, Cook et al. (1988) found a similar strong response in autonomic measures for focal phobia patients and a blunted reaction in more generally anxious patients. In neither experiment did this difference in physiological responses relate to differences in self-reported vividness of imagery, nor in reported emotional arousal during fearful imagery. 


\section{Negative Affectivity and Anxiety Pathology}

Cuthbert et al. (2003) also noted an inverse relationship across anxiety diagnoses between physiological reactivity and questionnaire-reported symptomatic anxiety and depression distress, and the frequency of mood-disorder comorbidity. In particular, specific phobia patients endorsed the least distress and had the lowest rates of comorbid depression, followed by patients diagnosed with social phobia, posttraumatic stress disorder (PTSD) and finally panic disorder with agoraphobia (PDA). Some theorists view the dimensional pattern of selfreport and interview-based comorbidity as representing a single, broad diathesis factor that underlies both anxiety and depression (e.g., Mineka, Watson, \& Clark, 1998; Krueger et al., 1998; Krueger, 1999) with those endorsing the highest symptom severity and comorbidity representing the extreme end of a single "internalizing factor" (Krueger \& Finger, 2001).

Accumulating evidence from both phenotypic and genotypic investigations of anxiety and mood disorder comorbidity further supports the notion of a single continuum that may underlie these disorders. For example, in an effort to determine the latent structure of anxiety and mood disorders, Krueger (1999) and later Vollebergh et al. (2001) showed that the comorbidity patterns among generalized anxiety disorder (GAD), major depression and dysthymia suggest a single "anxious-misery" factor whereas specific and social phobia, together with panic and agoraphobia, covaried in a "fear" factor, with both factors subsumed under a higher-order "internalizing factor", which might be construed as enduring negative affectivity/emotionality (Tellegen, 1982; Watson \& Clark, 1984).

Considerations of the underlying genetic and environmental risk factors in anxiety and mood disorders have also supported hypotheses of a single mediating dimension. Hettema et al. (2005) found genetic aggregation into two broad groups of anxiety disorders divided as panic, agoraphobia and GAD in one group versus the specific phobias in the other group-with social phobia intermediate between these. A prior investigation using the same twin registry (Kendler et al., 2003), this time including major depression, found that GAD, major depression, and, to some extent, panic loaded on the "anxious-misery" factor whereas animal and situational phobia comprised a separate "fear" factor. Other laboratories have also shown significant genetic correlation between the generalized symptomatology of panic disorder, GAD, and PTSD (Chantarujikapong et al., 2001; Scherrer et al., 2000). Taken together these data provide support for an initial hypothesis that a single dimension of stable negative affectivity may manifest as diagnostic variants organized by factors of fearfulness and anxious-misery.

\section{Is chronic negative affectivity a physiological dimension?}

The concept of an affective dimension that underlies differences among anxiety disorders is provocative. One weakness of this theorizing, however, lies in the narrowness of its supporting database. The relevant findings are derived almost entirely from self-report questionnaires and symptom assessment at interview. With a few notable exceptions (e.g., Irwin, Davidson, Kalin, Sorenson, \& Turski, 1998), the database generally does not include objective behavioral-task measures, physiological evidence of expressed emotion, or perhaps more importantly, brain based measures that could be associated with a dimensional factor and objectively confirm diagnostic differences. Considering the low correlations that have been repeatedly shown between reports of physiological symptoms and actual symptom expression (e.g., Buss, 1962, Lang, 1978, Mandler, Mandler, Kremen, \& Sholiton, 1961), this absence is a major concern. To give a specific example, are responses to items on the Anxious Arousal subscale of Watson and Clark's (1991) Mood and Anxiety Symptom Questionnaire (MASQ) such as —-Muscles twitched or trembled"; "Heart was racing or pounding"; "Hands were cold and sweaty" or related items from the State and Trait Anxiety Inventory (STAI, Spielberger, Gorsuch, Lushene, Vagg, \& Jacobs, 1983) including "I feel strained" and "I feel jittery"- 
actually related to the patient's physiology? Is negative affectivity just language behavior, or is there a physiological core that also varies inversely with a severity dimension?

\section{Recent Research on Emotional Imagery and the Anxiety Disorder Spectrum}

Research recently completed to confirm and extend the findings of Cuthbert and colleagues (2003), using an even larger sample of anxiety patients, continues to reveal significant diagnostic differences during emotional imagery. A new sample of 156 patients and healthy normal participants was studied at the University of Florida Fear and Anxiety Disorders Clinic (Lang, McTeague, \& Cuthbert, 2005; Lang, McTeague \& Cuthbert, 2007). The Anxiety Disorders Interview Schedule (ADIS-IV, Brown, DiNardo \& Barlow, 1994) was again used to determine DSM-IV diagnoses, resulting in four principal diagnostic groups (specific phobia, $\mathrm{n}=30$, social phobia, $\mathrm{n}=36$, panic disorder with agoraphobia (PDA), $n=27$, generalized anxiety disorder, $(\mathrm{GAD}) \mathrm{n}=26)$; and additionally, a demographically-matched, non-treatment seeking control group ( $\mathrm{n}=40)$. Whereas in the Cuthbert et al. (2003) study, participants memorized imagery scenes that were later recalled subsequent to tone cues, participants in the more recent investigation listened to auditory scripts and imagined the scenarios upon cue offset. Figure 3 depicts the structure of a single imagery trial.

\section{Diagnostic Differences in Startle Reactivity}

As illustrated in Figure 4 acoustic startle response to a probe presented during aversive imagery again resulted in the emergence of diagnostic differences, $p<.05$, with the largest blinks elicited by specific phobia compared to control participants, $p<.05$, and patients diagnosed with PDA, $p<.05$, or GAD, $p<.05$. Social phobia patients also clearly showed larger blinks than PDA, $p<.05$, and despite higher within-group variance, also tended to show greater potentiation than patients with GAD, $p=.08$. Overall, the data support the distinction made by Cuthbert et al. (2003) between fearful and anxious disorders: The specific and social phobia diagnoses represent the fearful group, as before, with PDA and GAD—a diagnosis new to the analysis - combining to form an anxious group. Again, it is the anxious who show significantly attenuated defensive reactivity during threatening or fearful imagery compared to the fearful specific and social phobia patients, $p<.01$.

In contrast to the group differences found during imagery of threat scenes, no differences emerged for startle reflexes elicited during a five-minute baseline prior to the imagery protocol. Furthermore, no group differences emerged in the magnitude of startle responding to the probes delivered between trials during the brief relaxation period (i.e., 18-30 second inter-trial interval). Rather, the group differences appear to be a specific function of differences among the anxiety disorders in affective recruitment during aversive imagery.

Rated distress-Is the diminished physiological reactivity of the "anxious" disorders due in part to reduced imaginal involvement? As measured by self-report ratings, there were no diagnostic group differences in rated unpleasantness (emotional valence) for threat imagery. There was, however, an interesting group difference in rated intensity (emotional arousal), $p<.01$ : Social phobia, PDA, and GAD patients actually rated threatening scenes as significantly more arousing than specific phobia or control participants-the opposite pattern than would be expected from the physiological data. For ratings of emotional dominance (the sense of being "in control" of one's reactions) during fear imagery, a group difference also emerged, $p<.01$, with PDA and GAD patients reporting less agency than control or specific phobia participants.

Personal Relevance-Consistent with the verbal reports of affective intensity during imagery, the pattern of exaggerated defensive reactivity among the more fearful versus the more anxious disorders does not appear to reflect a lack of personal relevance. Rather, the same 
pattern of reflex responding elicited during imagery of standard fear scenes emerged during idiographic, clinically relevant scenes tailored to each patient's principal problem. Specific and social phobia patients both demonstrated elevated startle during idiographic fear imagery compared to GAD, $p<.05$. Specific phobia patients also showed reliably enhanced fearpotentiation compared to PDA, $p<.05$.

Psychotropic Medication Usage-The aforementioned diagnostic differences in psychophysiological reactivity appear to be independent of psychotropic use. Fifty-one of the 119 patients studied indicated current use of prescribed medications for alleviating mental health symptoms. Most frequently, these medications were selective serotonin-reuptake inhibitors (SSRIs; 24\%) and/or benzodiazepines as needed (20\%). The effects of these and less frequently endorsed compounds (e.g., norepinephrine-dopamine reuptake inhibitors, 4\%; beta blockers, $1 \%$ ) were assessed by comparing baseline resting and imagery reactivity among the medicated and non-medicated individuals both for patients as a whole and within diagnosis. Considering either general psychotropic usage or more specific classes of drugs, no reliable effects emerged, perhaps due to the relatively small proportion of the sample on any single medication. However these null findings are consistent with prior psychophysiological studies of depression (Dichter, Tomarken, Shelton, \& Sutton, 2004; Dichter \& Tomarken, 2008; Forbes, Miller, Cohn, Fox, \& Kovacs, 2005; Rottenberg, Gross, \& Gotlib, 2005).

Similarly, no systematic diagnostic effects emerged in this research as a function of sex, age, or race.

\section{Diagnostic Differences in Negative Affectivity}

Whereas evaluative ratings of affective engagement, personal relevance of stimulus materials, demographics, and psychotropic medication status did not appear to covary with the pattern of defensive physiology, questionnaire-based indices of anxiety and depression symptomatology showed a strong inverse relationship. All five symptom subscales of the Mood and Anxiety Symptom Questionnaire (MASQ, Watson \& Clark, 1991) whether emphasizing anxiety or depression: 1 . proved to be highly correlated (i.e., $r=.63-.85$ ). and 2 . systematically increased across disorders (Figure 5), from specific phobia with the lowest scores to the highest scores for patients diagnosed with PDA and GAD at the end of this anxiety spectrum (Diagnostic Group, $p<.0001$; all univariate linear trends, $p<.01$ ). PDA and GAD patients differed on only one scale, MASQ-Anxious Arousal, with PDA showing the higher mean score. This pattern of increasing scores from phobic to more generally anxious disorders reappears when other frequently used questionnaires are analyzed, such as those indexing diffuse anxiety (STAI, Spielberger, et al., 1983), cognitive and somatic depression (BDI, Beck. Steer, \& Brown, 1996), and anxiety sensitivity (ASI, Reiss, Peterson, Gursky, \& McNally, 1986), $p<$. 0001, all univariate linear trends, $p<.01$.

As noted previously, these findings are consistent with data reported by Krueger and Finger (2001) in their application of item response theory to explore the extent to which anxiety and mood disorders are organized by a broad, higher-order factor rather than distinct entities. They found evidence for a unitary scale, with PDA and GAD patients scoring highest on what they termed an "internalizing" factor that was associated with greater functional impairment and more inpatient admissions. In short, evidence exists across laboratories and investigative methodologies in support of an anxiety disorder severity continuum characterized by progressive negative affectivity.

\section{Dimensional negative affectivity and potentiated startle}

Guided by the evident continuum of self-reported distress across diagnoses, patients as a whole were subsequently divided according to reported trait anxiety (STAI, Spielberger et al., 
1983) (i.e., lower quartile, middle two quartiles combined, and upper quartile) yielding low, moderate, and high symptom groups. As illustrated in the left panel of Figure 6 significant startle differences among groups classified in this manner were apparent, $p<.01$, with larger reflexes elicited during aversive imagery for those endorsing lower levels of chronic unspecified anxiety, compared to those endorsing either moderate, $p<.05$, or high symptomology, $p<.05$. In effect, lower levels of diffuse anxiety were associated with larger and more robust defensive reactivity. In contrast, reduced reactivity was found for the high trait anxious group.

Anxiety patients were then divided in terms of their endorsement of cognitive and somatic symptoms of depression (BDI; Beck et al., 1996) into low, moderate, and high symptom groups. A trend for an overall group difference emerged, $p=.09$, and planned comparisons indicated that the low symptom group elicited larger blinks during aversive imagery than did the high depression group, $p<.05$, as illustrated in the right panel of Figure 6 . In light of the high correlation between BDI and STAI scores in these patients $(r=0.75, p<.001)$, the similarity of their associations to fear potentiated startle is not surprising and further undergirds the notion of a single negative affectivity factor rather than separable syndromes of anxiety and depression.

\section{Three factors? Fear, anxiety, and depression}

To determine if the inhibitory effects of comorbid depression on startle potentiation are similar for putative "fearful" diagnoses (i.e., specific and social phobia) and more generalized "anxious" diagnoses (i.e., PDA and GAD), the patient sample was divided into four groups: "fearful" but without current major depression ( $\mathrm{n}=32)$; "fearful" with current depression $(\mathrm{n}=34)$; anxious without depression $(\mathrm{n}=25)$; "anxious" with major depression $(\mathrm{n}=28)$ (Figure 7 ). In this $2 \times 2$ factorial design, it was clear that the "fearful" patients (specific and social phobia) showed greater potentiation than the "anxious" patients, main effect, $p<.01$.

Furthermore, startle reactivity was consistently reduced for patients with comorbid depression, main effect, $p<.01$. No interaction was apparent: Follow-up comparisons showed that depression reliably attenuated startle in both "fearful", $p<.01$, and "anxious" disorders, $p<.01$. Notably, the "anxious" depressed group, which endorsed the most symptomatology, showed the most pronounced blunting, with reliable attenuation compared to all other groups, $p s<.05$, implicating a unitary, additive effect of diffuse anxiety and depression that results in its most extreme form in defensive impairment.

At the transition between fear and anxiety-The preceding results (Cuthbert et al., 2003; Lang et al., 2005; 2007) suggest that social phobia is a transition diagnosis on the anxiety spectrum between the focused fear reactivity seen in specific phobia and the diffuse, less reliable responses of the chronically anxious diagnoses (i.e., PDA/GAD). In a recent investigation of potential within-diagnosis variation in social phobia (McTeague et al., 2009), startle probe responses of patients $(n=75)$ and controls $(n=75)$ demographically matched for sex, age, race and gender were compared. In addition to considering differences in presence or absence of social phobia, the influences of diagnostic subtype (circumscribed, generalized) and comorbid depression were assessed. As a whole, social phobia patients exceeded controls in startle reflex responding during imagery of social threat (both idiographic and standard) whereas the groups evinced commensurate reactivity to contents depicting adaptive, commonly shared fears (survival threat). To assess diagnostic sybtype effects, patients were further defined according to whether their negative evaluation fears were limited to performance contexts (circumscribed social phobia) or evident across performance and interaction domains (generalized social phobia). Patients with circumscribed performance phobia were similar to controls, with the exception of more robust fear potentiation specifically to idiographic, performance fear imagery, $p<.05$. In contrast, generalized social phobia patients demonstrated 
heightened sensitivity to a broader range of fear contents, exceeding controls in startle reflex responses to both standard social, $p<.05$, and idiographic social fear scenes, $p<.05$. When comorbid depression status was considered in generalized phobia, patients with depression showed attenuation of fear-potentiated startle relative to the non-depressed, $p<.05$ (Figure 8) -as for the entire anxiety spectrum.

Not only did the startle reflex data across social phobia subtypes parallel the entire anxiety spectrum, so too did the reliable increments in self-reported anxiety and depression from circumscribed phobia, to generalized non-depressed phobia, and finally generalized, depressed phobia (Figure 9). Furthermore the same reliable pattern emerged for self-reported disorder chronicity; essentially, defense system activation in social phobia appears to vary systematically with length of illness. That is, circumscribed phobia patients report the fewest symptoms and the shortest disorder duration, but show the most robust cue-specific defensive engagement; in non-depressed, generalized phobia patients the disorder is of longer duration, more symptoms are reported, and there is an associated broader defensive sensitivity. However, with a further increase in chronicity and comorbid depression, generalized phobia patients show a relative, overall attenuation of the fear potentiated startle, suggesting failure of expected defensive engagement.

\section{A compromised defense system?}

Upon initial consideration the reliable covariance between increased severity of psychopathology and reduced defensive reactivity observed in these studies seems paradoxical. However, an animal model of conditioned defeat or "learned helplessness" in which all responding is reduced in aversive contexts, may be pertinent in interpreting these data (Seligman, 1975). Conditioned defeat in laboratory animals was observed following exposure to repeated, uncontrollable, non-signaled aversive stimulation (e.g., electric shock). In this context, the defense system appeared to shut down and the animal remained immobile, unable to respond appropriately, even if new escape routes were provided. Pavlov earlier (1927) and later Liddell (1956) noted a similar suppression of defensive reactivity subsequent to extreme, unpredictable stress that was accompanied by maladaptive behavior even observable outside the experimental context. Pertinent to the human startle data reviewed here, Davis and Astrachan (1978) observed a non-monotonic relationship between fear-potentiated startle and shock intensity in rats. That is, the most robust potentiation emerged at intermediate levels of shock with lesser potentiation at both low and high shock intensities. Taken together, these findings tentatively suggest that attenuation of startle responding in anxiety disorders may in part be a function of intense, unpredictable and prolonged stress.

Furthermore, the finding that blunting of fear-potentiated startle is associated with anxiety disorder chronicity (McTeague et al., 2009) has a parallel in animal research. For example, rats exposed to brief (i.e., 10 days) and/or less severe "resident/intruder" stress demonstrate hypervigilance and hyperarousal (i.e., decreased reaction time to both the original aggressor and the neutral unfamiliar), whereas rats exposed to longer duration stress (20-30 days) develop more generalized anxiety and depressive-like symptoms-including passivity, limited movement and reduced communication behaviors - that persist even in the absence of the aggressor (Avgustinovich, Kovalenko, \& Kudryavtseva, 2005). Concerning the potentional neural underpinnings of defensive hypo-activity, Maier and colleagues (1993) initially exposed rats to inescapable shock thus inducing observable deficits in defensive mobilization. Next, the investigators lesioned the central nucleus of the amygdala, and found no rebound of adaptive defensive behaviors. Instead, lesions of the bed nucleus stria terminalis resulted in return of the defensive repertoire (Hammack, Richey, Watkins, \& Maier, 2004).

Overall, much of the emerging animal research on anxiety and depression implicate the role of chronic unavoidable stress and secondary plasticity of the bed nucleus stria terminalis in 
generalized anxiety and depressive-like defensive impairments. These findings are particularly germane to the previously reviewed findings that fear-potentiated startle in anxiety patients during narrative imagery has shown a monotonic decrease from the punctuated and reliable defensive reactivity of specific phobia to the unreliable and attenuated reactivity of the more chronically anxious and depressed PDA and GAD. Davis and colleagues (e.g., Walker et al., 2003) have shown that fear appears to deviate from anxiety in terms of the preferential activation of the short-acting central nucleus of the amygdala or the longer-acting bed nucleus stria terminalis. Similar to human phenotypic and genotypic studies animal studies appear to be implicating similar processes and underpinnings to generalized anxiety and depression. Perhaps the bed nucleus stria terminalis, rather than the central nucleus of the amygdala typically responsible for fear potentiation, is preferentially activated in anxiety patients with chronic high negative affect and that, coupled with deficient medial prefrontal cortical activation (e.g., Shin et al., 2001), diffuse and generalized defensive reactivity interferes with reliable, punctate recruitment upon exposure to a threatening imagery cue.

\section{Future directions: Fear and human brain function}

As described at the outset of this paper, emotional imagery is presumed to elicit essentially the same physiological responses (both peripherally and centrally) evoked during actual experience, minus the observable motor execution. In two recent functional magnetic resonance imaging (fMRI) studies, neural activation patterns in healthy control participants were assessed while they imagined experiencing emotional events (Sabatinelli, Lang, \& Bradley, 2006, Costa, Versace, Bradley, \& Lang, 2008). The data indicated that, at the onset of imagery, regions implicated in aversive motivation (amygdala, dorsomedial thalamus), working memory (parahippocampal gyrus, dorsolateral caudate), semantic processing (left inferior frontal gyrus) and preparation and simulation of action (pre- and supplementary motor areas, cerebellum) were strongly enhanced during unpleasant arousing relative to neutral events. The activation of these regions, many that subserve overt planning and executing action (e.g., Gao, Chen, \& Gong, 2008), support the idea that emotional imagery is a process of response mobilization-discernible in central as well as in peripheral changes-as proposed in bio-informational theory $(1979,1985)$.

In subsequent research (Costa et al., 2008), the same regional patterns of emotional sensitivity emerged during unpleasant imagery in a group of anxiety patients $(\mathrm{n}=13)$ and healthy controls $(n=13)$. Overall, in this small sample patients and controls showed the same pattern of activation, including commensurate amygdala increases during unpleasant versus neutral imagery (Figure 10). Interestingly, however, the diagnostically more "fearful" anxiety patients $(\mathrm{n}=7)$ showed significantly greater activity, $p<.05$ corrected, in areas relevant for motor planning and control (SMA, Figure 11). These data are consistent with the heightened reflex responses in the psychophysiological laboratory of fearful relative to anxious patients and promote the premise that disorders of circumscribed fearfulness are characterized by associative neural networks that more strongly activate dispositions to avoid or escape (Lang, 1979, 1985).

\section{Conclusions}

The research considered here supports the concept of an anxiety disorder spectrum characterized by increasing severity of broad negative affectivity or negative emotionality, and by what appears to be a reciprocal diminution in defensive reactivity. In this view, "fear" is a readiness to respond defensively to anticipated or imagined threat, and a major spectrum dimension that characterizes specific and social phobia, distinguishing these diagnoses from panic with agoraphobia and generalized anxiety disorder. Furthermore, increasing 
generalization of anxious apprehension and arousal and the presence of comorbid depression additively attenuate defensive reflexive activity.

The reviewed research highlights the discordance between physiological reactivity and verbal report of anxious arousal, suggesting that reliance on interview and questionnaire assessment -without psychophysiological measures-may obscure important indicants of defensive system integrity. The available evidence underscores the utility of reflex measures in honing differential diagnosis and shows their significant covariation with the determining neural circuits in the brain.

Finally, the preliminary neuroimaging data encourages the use of fMRI in future studies of emotional imagery differences across the anxiety spectrum. It will be important to determine if diagnostic differences in fear reflex potentiation are accompanied by systematic differences in brain function, and if the neural circuitry of defense is indeed disrupted in the context of chronic, diffuse anxiety and depression. The long-term aim is, of course, to develop a diagnostic system for the anxiety and mood disorders that is quantitative, based on psychophysiological and neurophysiological measures that will improve prognosis and treatment planning, and facilitate the development of more powerful, better-targeted therapies.

\section{Acknowledgments}

This work was supported in part by National Institute of Mental Health grant (P50 MH72850) to the Center for the Study of Emotion and Attention (CSEA), University of Florida, Gainesville, FL, and a NRSA Research Fellowship (F31 MH069048) to the second author.

Many thanks to various members of the Center for the Study of Emotion and Attention for their assistance, especially Bruce Cuthbert, Marie-Claude Laplante, Margaret Bradley, Vincent Costa, and Cyd Strauss.

\section{References}

American Psychiatric Association. Diagnostic and statistical manual of mental disorders. Vol. 4th ed.. Author; Washington, DC: 1994.

Amaral, DG.; Price, JL.; Pitkanen, A.; Carmichael, ST. Anatomical organization of the primate amygdaloid complex. In: Aggleton, JP., editor. The amygdala: Neurobiological aspects of emotion, memory, and mental dysfunction. Wiley; New York: 1992. p. 1-66.

Avgustinovich DF, Kovalenko IL, Kudryavtseva NN. A model of anxious depression: persistence of behavioral pathology. Neuroscience \& Behavioral Physiology 2005;35:917-24. [PubMed: 16270173]

Barlow, DH. True alarms, false alarms, and learned anxiety. In: Barlow, DH., editor. Anxiety and its disorders: The nature and treatment of anxiety and panic. Vol. 2nd ed.. Guilford Press; New York: 2002. p. 219-251.

Bradley MM, Codispoti M, Cuthbert BN, Lang PJ. Emotion and motivation I: Defensive and appetitive reactions in picture processing. Emotion 2001a;1(3):276-98. [PubMed: 12934687]

Bradley MM, Codispoti M, Sabatinelli D, Lang PJ. Emotion and motivation II: Sex differences in picture processing. Emotion 2001b;1:300-319. [PubMed: 12934688]

Bradley MM, Moulder B, Lang PJ. When good things go bad: the reflex physiology of defense. Psychological Science 2005;16(6):468-73. [PubMed: 15943673]

Brown, TA.; DiNardo, PA.; Barlow, DH. Anxiety Disorders Interview Schedule for DSM-IV. Graywood Publications; Albany, NY: 1994.

Buss AH. Critique and notes: Two anxiety factors in psychiatric patients. Journal of Personality and Social Psychology 1962;65:426-427.

Chantarujikapong SI, Scherrer JF, Xian H, Eisen SA, Lyons MJ, Goldberg J, et al. A twin study of generalized anxiety disorder symptoms, panic disorder symptoms and post-traumatic stress disorder in men. Psychiatry Research 2001;103(23):133-45. [PubMed: 11549402] 
Cook EW III, Melamed BG, Cuthbert BN, McNeil DW, Lang PJ. Emotional imagery and the differential diagnosis of anxiety. Journal of Consulting and Clinical Psychology 1988;56:734-740. [PubMed: 3192790]

Costa, VD.; Versace, F.; Bradley, MM.; Lang, PJ. Functional connectivity of premotor and limbic regions during emotional imagery Program Number 5766. Society for Neuroscience, CD-ROM; Washington, DC: 2008.

Cuthbert BN, Lang PJ, Strauss C, Drobes D, Patrick CJ, Bradley MM. The psychophysiology of anxiety disorder: Fear memory imagery. Psychophysiology 2003;40:407-422. [PubMed: 12946114]

Davis M, Astrachan DI. Conditioned fear and startle magnitude: effects of different footshock or backshock intensities used in training. Journal of Experimental Psychology: Animal Behavior Processes 1978;4(2):95-103. [PubMed: 670892]

Davis, M. The role of the amygdala in conditioned and unconditioned fear and anxiety. In: Aggleton, JP., editor. The amygdala. Vol. 2. Oxford University Press; Oxford, UK: 2000. p. 213-287.

Davis, M.; Lang, PJ. Emotion. In: Gallagher, M.; Nelson, RJ.; Weiner, IB., editors. Handbook of Psychology, Volume 3: Biological psychology. John Wiley \& Sons, Inc.; New Jersey: 2003. p. 405-439.

Dichter GS, Tomarken AJ, Shelton RC, Sutton SK. Early- and late-onset startle modulation in unipolar depression. Psychophysiology 2004;41(3):433-40. [PubMed: 15102129]

Dichter GS, Tomarken AJ. The chronometry of affective startle modulation in unipolar depression. Journal of Abnormal Psychology 2008;117(1):1-15. [PubMed: 18266482]

Forbes EE, Miller A, Cohn JF, Fox NA, Kovacs M. Affect-modulated startle in adults with childhoodonset depression: relations to bipolar course and number of lifetime depressive episodes. Psychiatry Research 2005;134(1):11-25. [PubMed: 15808286]

Frijda NH. Emotion, cognitive structure, and action tendency. Cognition and Emotion 1987;1(3):115143.

Gao Q, Chen H, Gong Q. Evaluation of the effective connectivity of the dominant primary motor cortex during bimanual movement using Granger causality. Neuroscience Letters 2008;443(1):1-6. [PubMed: 18656524]

Gloor, P. Amygdala. In: Field, J., editor. Handbook of physiology: Sect 1. Neurophysiology. American Physiological Society; Washington, DC: 1960. p. 1395-1420.

Gray, TS. Autonomic neuropeptide connections of the amygdala. In: Tache, Y.; Morley, JE.; Brown, MR., editors. Neuropeptides and stress. Springer; New York: 1989. p. 92-106.

Grillon C, Ameli R, Woods SW, Merikangas K, Davis M. Fear-potentiated startle in humans: Effects of anticipatory anxiety on the acoustic blink reflex. Psychophysiology 1991;28:588-595. [PubMed: 1758934]

Hamm AO, Cuthbert BN, Globisch J, Vaitl D. Fear and startle reflex: Blink modulation and autonomic response patterns in animal and mutilation fearful subjects. Psychophysiology 1997;34:97-107. [PubMed: 9009813]

Hamm AO, Greenwald MK, Bradley MM, Lang PJ. Emotional learning, hedonic change, and the startle probe. Journal of Abnormal Psychology 1993;102:453-465. [PubMed: 8408958]

Hammack SE, Richey KJ, Watkins LR, Maier SF. Chemical lesion of the bed nucleus of the stria terminalis blocks behavioral consequences of uncontrollable stress. Behavioral Neuroscience 2004;118:443-448. [PubMed: 15113272]

Hettema JM, Prescott CA, Myers JM, Neale MC, Kendler KS. The structure of genetic and environmental risk factors for anxiety disorders in men and women. Archives of General Psychiatry 2005;62(2): 182-9. [PubMed: 15699295]

Hoehn-Saric R, McLeod DR, Funderbunk F, Kowalski P. Somatic symptoms and physiologic responses in generalized anxiety disorder and panic disorder: an ambulatory monitor study. Archives of General Psychiatry 2004;61:913-921. [PubMed: 15351770]

Irwin W, Davidson R, Kalin H, Sorenson J, Turski P. Relations between human amygdala activation and self-reported dispositional affect. Journal of Cognitive Neuroscience, [Suppl.] 1998:S109.

Kapp, BS.; Pascoe, JP.; Bixler, MA. The amygdala: a neuroanatomical systems approach to its contribution to aversive conditioning. In: Butters, N.; Squire, LS., editors. The neuropsychology of memory. Guilford Press; New York: 1984. p. 473-488. 
Kendler KS, Prescott CA, Myers J, Neale MC. The structure of genetic and environmental risk factors for common psychiatric and substance use disorders in men and women. Archives of General Psychiatry 2003;60(9):929-37. [PubMed: 12963675]

Konorski, J. Integrative activity of the brain: An interdisciplinary approach. University of Chicago Press; Chicago: 1967.

Krueger RF. The structure of common mental disorders. Archives of General Psychiatry 1999;56:921926. [PubMed: 10530634]

Krueger RF, Caspi A, Moffitt TE, Silva PA. The structure and stability of common mental disorders (DSM-III-R): a longitudinal-epidemiological study. Journal of Abnormal Psychology 1998;107(2): 216-27. [PubMed: 9604551]

Krueger RF, Finger MS. Using item response theory to understand comorbidity among anxiety and unipolar mood disorders. Psychological Assessment 2001;13:140-151. [PubMed: 11281035]

Lang PJ. Imagery in therapy: An information processing analysis of fear. Behavior Therapy 1977;8:862886.

Lang, PJ. Language, imagery, and emotion. In: Pliner, P.; Blankstein, KR.; Spigel, IM., editors. Advances in study of emotion and affect: Vol. 5. Perceptions of emotion in self and others. Plenum; New York \& London: 1978. p. 107-117.

Lang PJ. A bio-informational theory of emotional imagery. Psychophysiology 1979;16:495-512. [PubMed: 515293]

Lang, PJ. The cognitive psychophysiology of emotion: Fear and anxiety. In: Tuma, AH.; Maser, JD., editors. Anxiety and the anxiety disorders. Erlbaum; Hillsdale, NJ: 1985. p. 131-170.Reprinted in Psychotherapeutisch Pasport, 3(2), 3-62 (1985)

Lang, PJ. The motivational organization of emotion: Affect-reflex connections. In: VanGoozen, S.; Van de Poll, NE.; Sergeant, JA., editors. Emotions: Essays on emotion theory. Erlbaum; Hillsdale, NJ: 1994. p. 61-93.

Lang, PJ.; Bradley, MM. Appetitive and defensive motivation is the substrate of emotion. In: Elliott, A., editor. Handbook of approach and avoidance motivation. Taylor \& Francis Group; New York, NY: 2008. p. 51-66.

Lang PJ, Davis M. Emotion, motivation, and the brain: Reflex foundations in animal and human research. Progress in Brain Research 2006;156:3-34. [PubMed: 17015072]

Lang PJ, Levin DN, Miller GA, Kozak MJ. Fear imagery and the psychophysiology of emotion: The problem of affective response integration. Journal of Abnormal Psychology 1983;92:276-306. [PubMed: 6619405]

Lang, PJ.; McTeague, LM.; Cuthbert, BN. Fearful imagery and the anxiety disorder spectrum. In: Rothbaum, BO., editor. Pathological anxiety: Emotional processing in etiology and treatment. Guilford Press; New York: 2005. p. 56-77.

Lang, PJ.; McTeague, LM.; Cuthbert, BN. Fear, anxiety, depression, and the anxiety disorder spectrum: A psychophysiological analysis. In: Treat, T.; Baker, T., editors. Psychological clinical science: Recent advances in theory and practice. Integrative perspectives in honor of Richard M. McFall. Lawrence Erlbaum Associates; Mahwah, NJ: 2007. p. 167-195.

LeDoux J. The emotional brain, fear, and the amygdala. Cellular and Molecular Neurobiology 2003;23 (45):727-38. [PubMed: 14514027]

Liddell, HS. Emotional hazards in animals and man. Charles C. Thomas; Springfield, Illinois: 1956.

Maier SF, Grahn RE, Kalman BA, Sutton LC, Wiertelak EP, Watkins LR. The role of the amygdala and dorsal raphe nucleus in mediating the behavioral consequences of inescapable shock. Behavioral Neuroscience 1993;107:377-388. [PubMed: 8484901]

Mandler G, Mandler JM, Kremen I, Sholiton R. The response to threat: Relations among verbal and physiological indices. Psychological Monographs 1961;75Whole No. 513

McNeil DW, Vrana SR, Melamed BG, Cuthbert BN, Lang PJ. Emotional imagery in simple and social phobia: Fear versus anxiety. Journal of Abnormal Psychology 1993;102:212-225. [PubMed: 8315134]

McTeague LM, Lang PJ, Laplante M-C, Cuthbert BN, Strauss CC, Bradley MM. Fearful imagery in social phobia: Generalization, comorbidity, and physiological reactivity. Biological Psychiatry 2009;65(5):374-382. [PubMed: 18996510] 
Miller GA, Levin DN, Kozak MJ, Cook EW III, McLean A Jr. Lang PJ. Individual differences in imagery and the psychophysiology of emotion. Cognition and Emotion 1987;1:367-390.

Mineka S, Watson D, Clark LA. Comorbidity of anxiety and unipolar mood disorders. Annual Review of Psychology 1998;49:377-412.

Pavlov, IP. Conditioned reflexes. Oxford University Press; Oxford: 1927.

Reiss S. Expectancy model of fear, anxiety, and panic. Clinical Psychology Review 1991;11:141-153.

Reiss S, Peterson RA, Gursky DM, McNally RJ. Anxiety sensitivity, anxiety frequency and the prediction of fearfulness. Behaviour Research and Therapy 1986;24:1-8. [PubMed: 3947307]

Rottenberg J, Gross JJ, Gotlib IH. Emotion context insensitivity in major depressive disorder. Journal of Abnormal Psychology 2005;114(4):627-39. [PubMed: 16351385]

Sabatinelli D, Bradley MM, Fitzsimmons JR, Lang PJ. Parallel amygdala and inferotemporal activation reflect emotional intensity and fear relevance. Neuroimage 2005;24(4):1265-70. [PubMed: 15670706]

Sabatinelli D, Bradley MM, Lang PJ. Affective startle modulation in anticipation and perception. Psychophysiology 2001;38(4):719-22. [PubMed: 11446586]

Sabatinelli D, Lang PJ, Bradley MM, Flaisch T. The neural basis of narrative imagery: emotion and action. Progess in Brain Research 2006;156:97-106.

Scherrer JF, True WR, Xian H, Lyons MJ, Eisen SA, Goldberg J, et al. Evidence for genetic influences common and specific to symptoms of generalized anxiety and panic. Journal of Affective Disorders 2000;57(13):25-35. [PubMed: 10708813]

Seligman, MEP. Helplessness: On depression, development and death. Freeman; San Francisco: 1975.

Shin LM, Whalen PJ, Pitman RK, Bush G, Macklin ML, Lasko NB, Orr SP, McInerney SC, Rauch SL. An fMRI study of anterior cingulate function in posttraumatic stress disorder. Biological Psychiatry 2001;50(12):932-42. [PubMed: 11750889]

Spielberger, CD.; Gorsuch, RL.; Lushene, PR.; Vagg, PR.; Jacobs, GA. Manual for the State-Trait Anxiety Inventory. Consulting Psychologists Press, Inc.; Palo Alto, CA: 1983.

Tellegen, A. Brief manual for the Multidimensional Personality Questionnaire. University of Minnesota; Minneapolis: 1982. Unpublished manuscript

Vollebergh WA, Iedema J, Bijl RV, de Graaf R, Smit F, Ormel J. The structure and stability of common mental disorders: the NEMESIS study. Archives of General Psychiatry 2001;58(6):597-603. [PubMed: 11386990]

Vrana SR, Lang PJ. Fear imagery and the startle probe reflex. Journal of Abnormal Psychology 1990;99:181-189.

Walker DL, Toufexis DJ, Davis M. Role of the bed nucleus of the stria terminalis versus the amygdala in fear, stress, and anxiety. European Jouranl of Pharmacology 2003;463:199-216.

Watson D, Clark LA. Negative affectivity: The disposition to experience aversive emotional states. Psychological Bulletin 1984;96(3):465-490. [PubMed: 6393179]

Watson, D.; Clark, LA. The Mood and Anxiety Symptom Questionnaire. University of Iowa, Department of Psychology; Iowa City: 1991. Unpublished manuscript

Weerts TC, Lang PJ. Psychophysiology of fear imagery: Differences between focal phobia and social performance anxiety. Journal of Consulting and Clinical Psychology 1978;46:1157-1159. [PubMed: 701554]

Wolpe, J.; Lang, P. Fear Survey Schedule. Educational and Industrial Testing Service; San Diego, CA: 1969. 


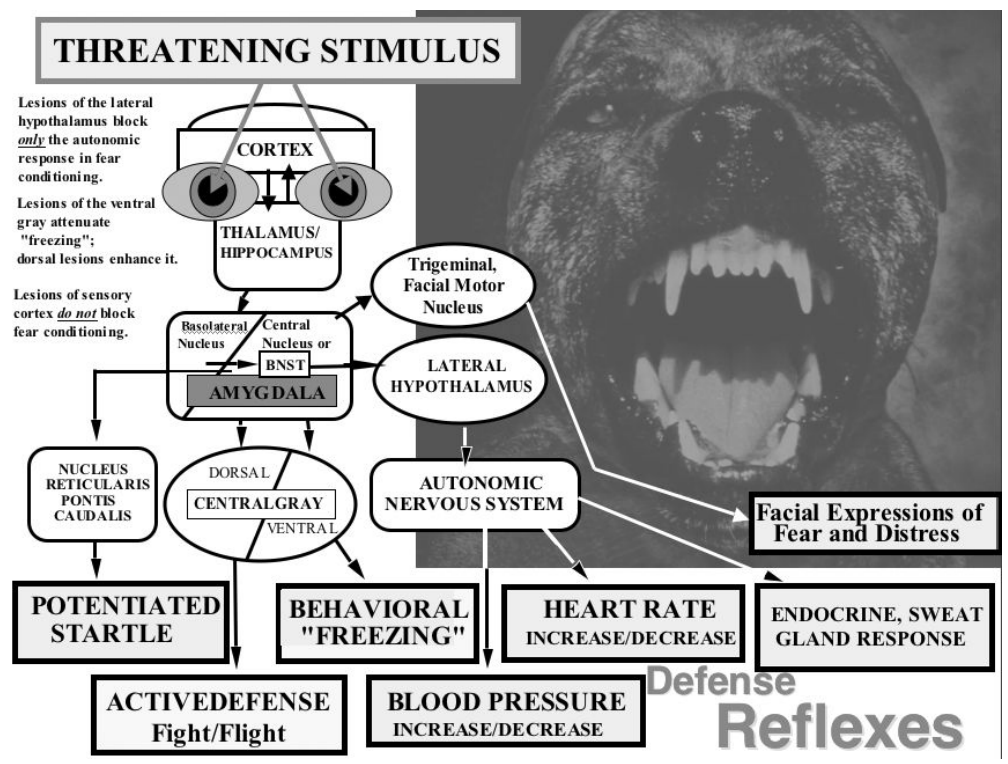

Figure 1.

Schematic diagram of the outputs of the basolateral nucleus of the amygdala to various target structures, and the subsequent outputs and targets of the amygdala's central nucleus and lateral basal nucleus of the stria terminalis (BNST; the "extended" amygdala). Known and possible functions of these connections are briefly indicated (adapted from Davis \& Lang, 2006). 


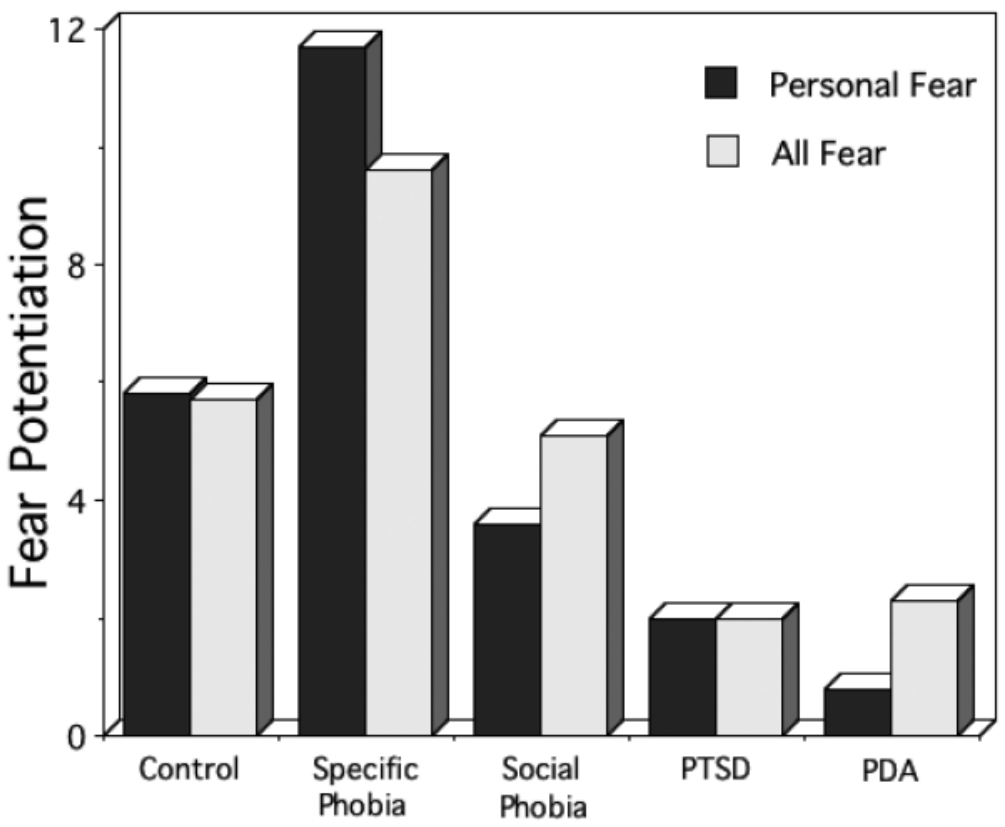

Diagnosis

Figure 2.

Startle potentiation during fear imagery by principal diagnostic group (PTSD=posttraumatic stress disorder; PDA=panic disorder with agoraphobia). The data presented include the magnitude of startle during personal fear imagery, and the average magnitude of all fear imagery contents (T-score differences from neutral imagery; adapted from Cuthbert et al., 2003). 


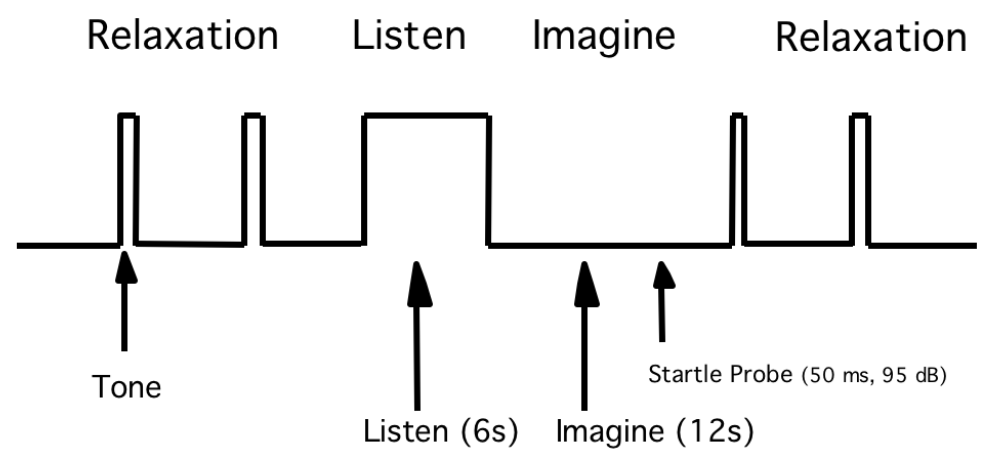

Standard Script Exemplars:

Animal Threat "I recoil as the large dog strains forward, snarling with teeth bared, and leaps out at me."

Human Threat "Alone in an alley my heart pounds in fear as, knives out, laughing with menace, the street gang surrounds me."

Social Threat "My heart pounds in the suddenly silent room; everyone is watching me, waiting to hear what I will say."

Figure 3.

Trial structure and sample scenes. Top: A single trial consisted of initial tone-cued, relaxation, a 6-second auditory script presentation followed by 12-second imagery of the described scene, and finally a tone-cued return to relaxation. Startle probes were presented once or twice from 4 to 11.5 seconds into the imagery period and during intertrial intervals. Bottom: Exemplar scripts depicting standard fear scenes. 


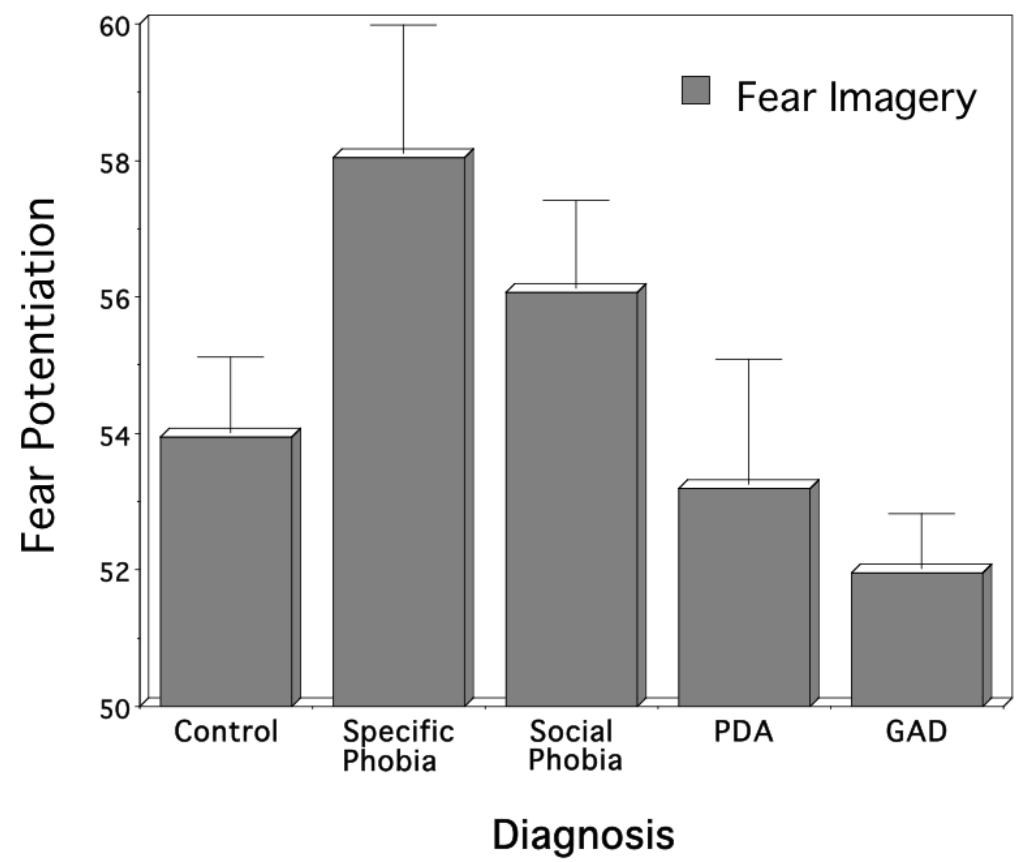

Figure 4.

Mean startle reflex responses during standard fear imagery by principal diagnostic group (PDA=panic disorder with agoraphobia; $\mathrm{GAD}=$ generalized anxiety disorder). Imagery responses are standardized to the distribution of responses during intertrial intervals (mean ITI response magnitude $=50$ ). Error bars refer to standard error of the mean. 


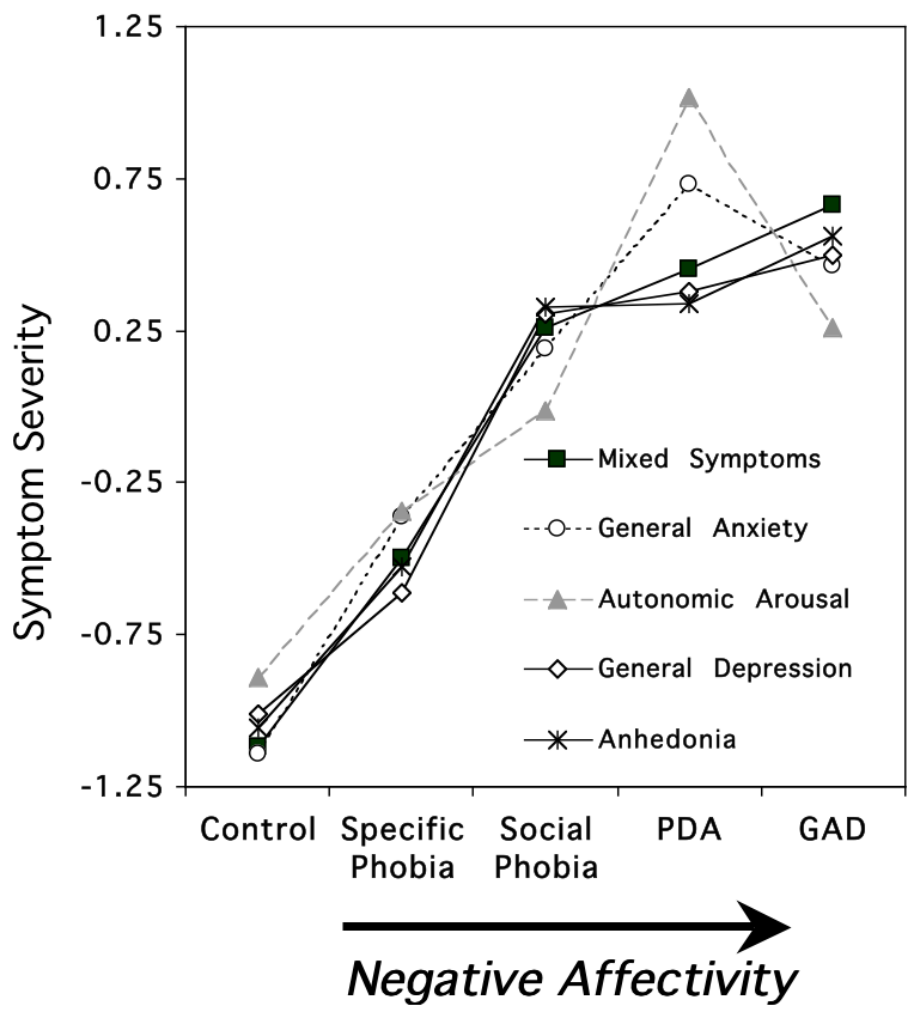

Figure 5.

Mean questionnaire responses (standardized across participants; z-score) by principal diagnostic group (PDA=panic disorder with agoraphobia; GAD=generalized anxiety disorder) showing a consistent pattern of increasing self-reported distress from phobic to more generally anxious disorders. Questionnaires corresponded to the five scales of the Mood and Anxiety Symptom Questionnaire (MASQ: General Distress Anxiety, General Distress Depression, General Distress Mixed Symptoms of Anxiety and Depression, Anhedonic Depression, Anxious Arousal (Watson and Clark, 1991)). 

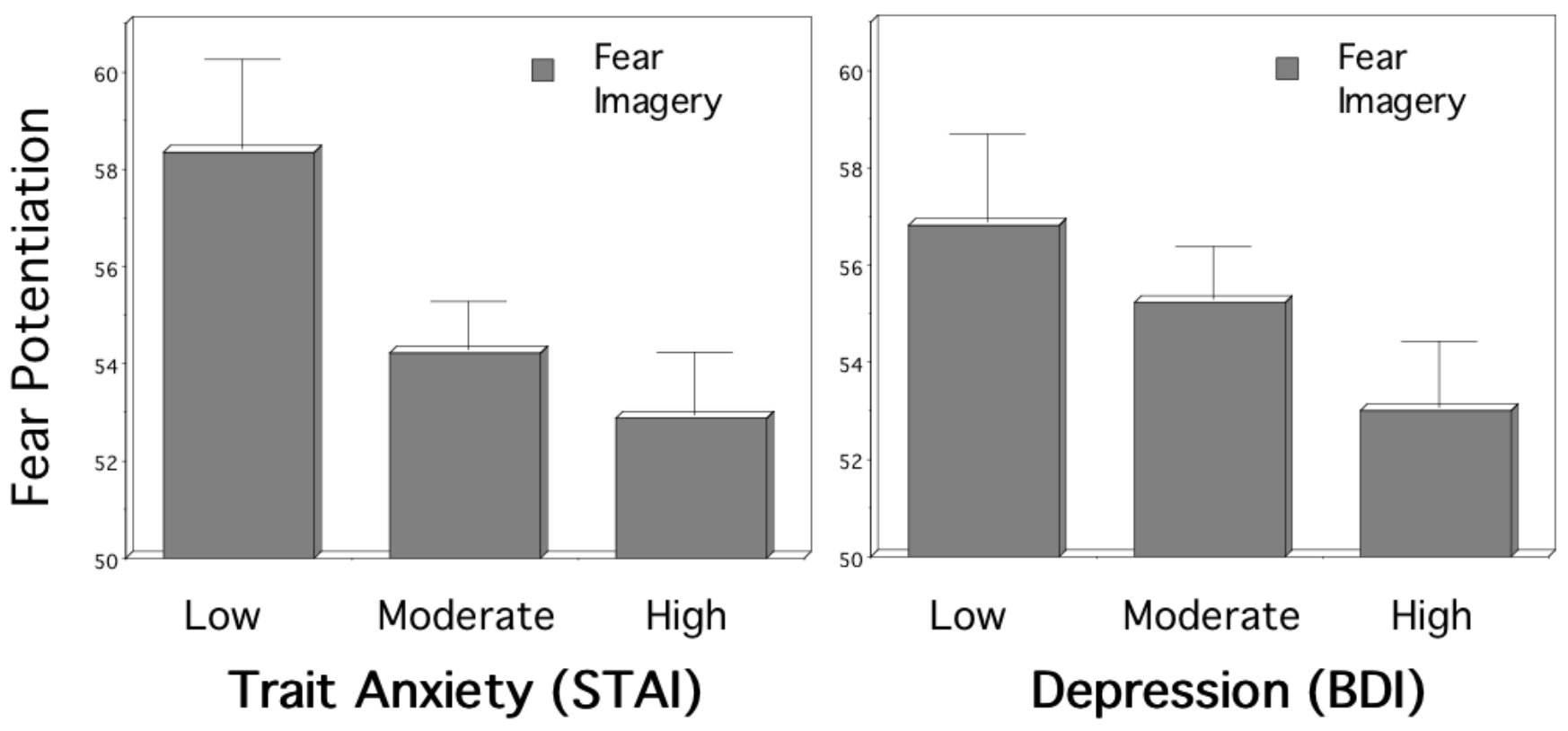

Figure 6.

The left panel depicts the trait anxiety (STAI; Spielberger et al., 1983) and the right panel depicts depression (BDI; Beck et al., 1996) symptom level differences in blink magnitude to a startle probe administered during imagery of standard fear scripts (standardized to the distribution of responses during intertrial intervals; mean ITI response magnitude $=50$ ). Error bars refer to standard error of the mean. Lower levels of trait anxiety and depression predict larger and more robust defensive reactivity. 


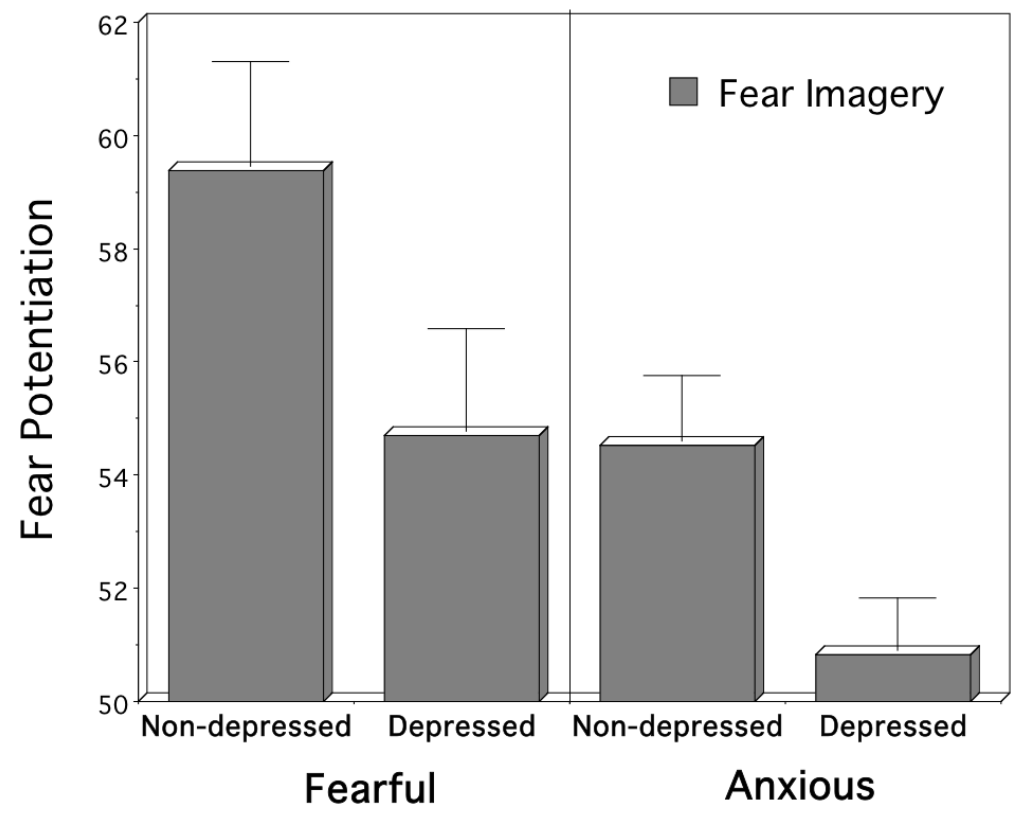

Figure 7.

Mean startle reflex responses during standard fear imagery for fearful (specific and social phobia) versus anxious (PDA and GAD) disorders, with and without comorbid depression (standardized to the distribution of responses during intertrial intervals; mean ITI response magnitude $=50$ ). The principal presenting problem (i.e., phobia or anxiety) and comorbid depression additively influence physiological reactivity. 


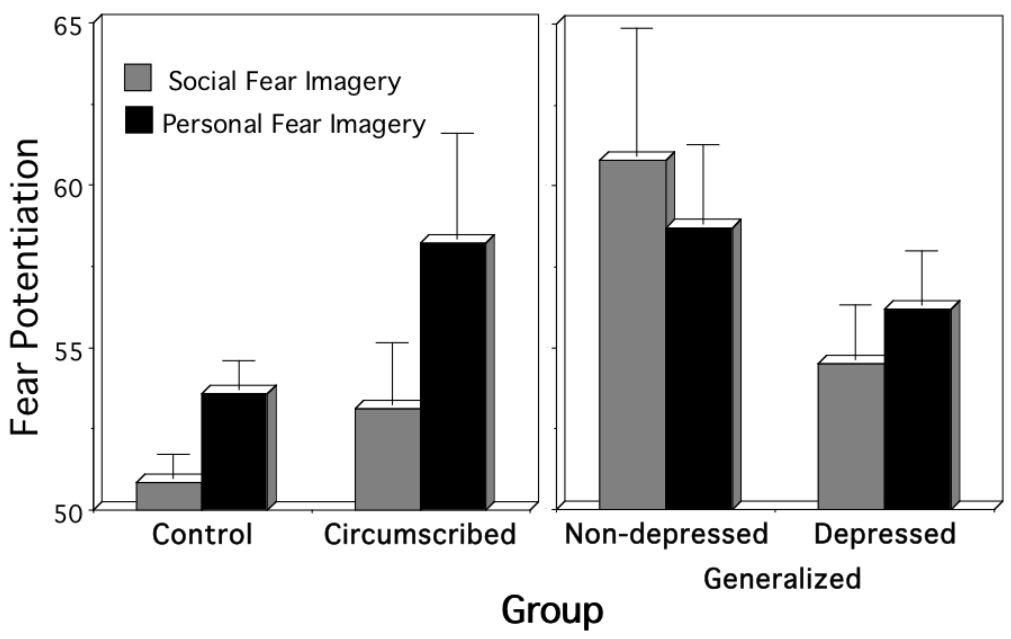

Figure 8.

Mean startle reflex responses during social threat and personal fear imagery for the control, circumscribed social phobia, generalized social phobia without comorbid depression, and generalized social phobia with comorbid depression groups (standardized to the distribution of responses during intertrial intervals; mean ITI response magnitude=50). Error bars refer to standard error of the mean. 

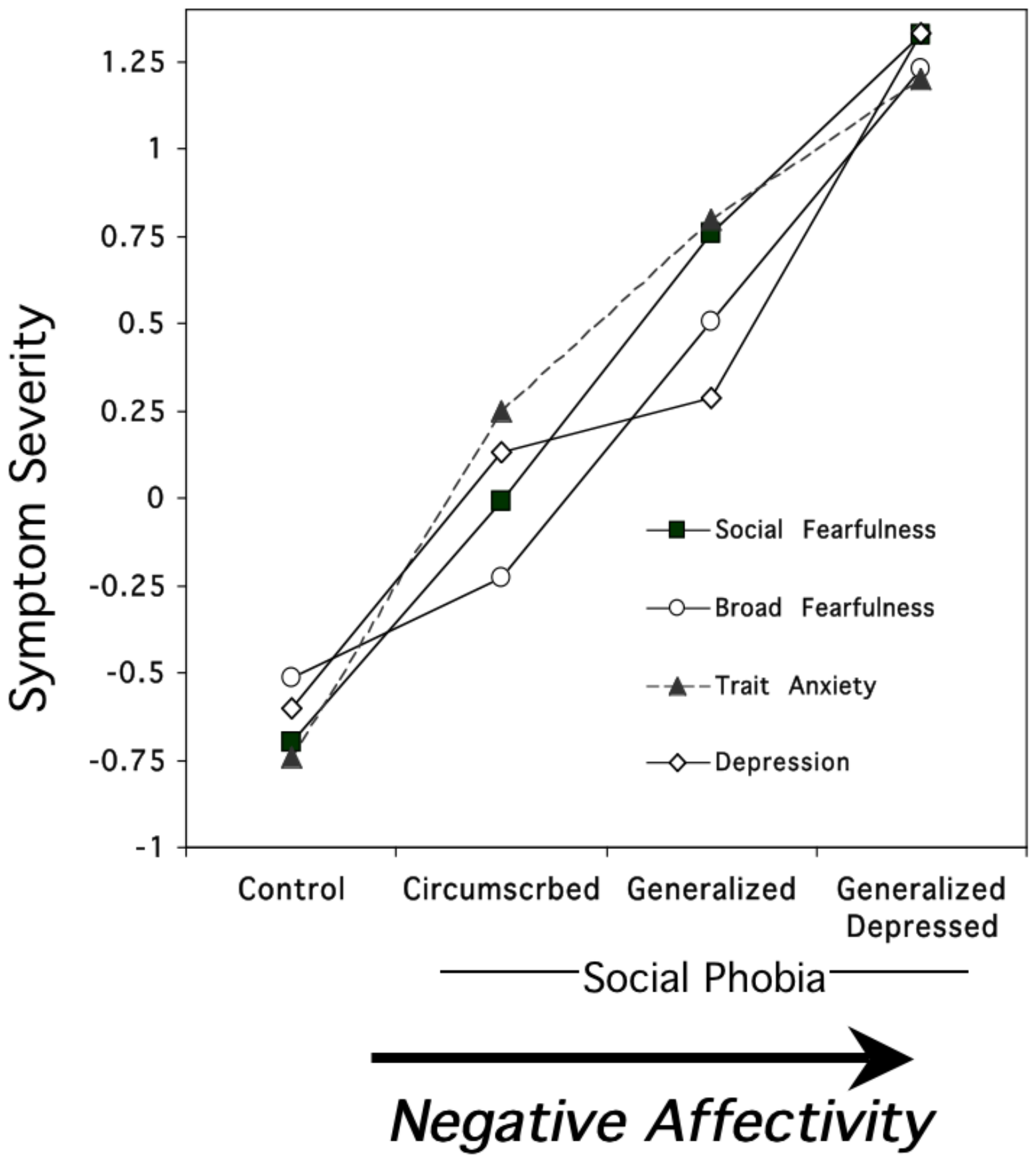

Figure 9.

Mean questionnaire for controls and subtypes of social phobia (standardized across participants; z-score). The same negative affectivity continuum evident across anxiety disorders (Figure 5) is observed within social phobia diagnosis. Social Fearfulness = Social Fearfulness subscale of the Fear Survey Schedule (Wolpe \& Lang, 1969); Broad Feafulness; = Fear Survey Schedule total score (Wolpe \& Lang, 1969); STAI-Trait = State Trait Anxiety Inventory (Spielberger et al., 1983); Depression=Beck Depression Inventory (Beck et al., 1996). 
Amygdala Contrast: Unpleasant > Neutral

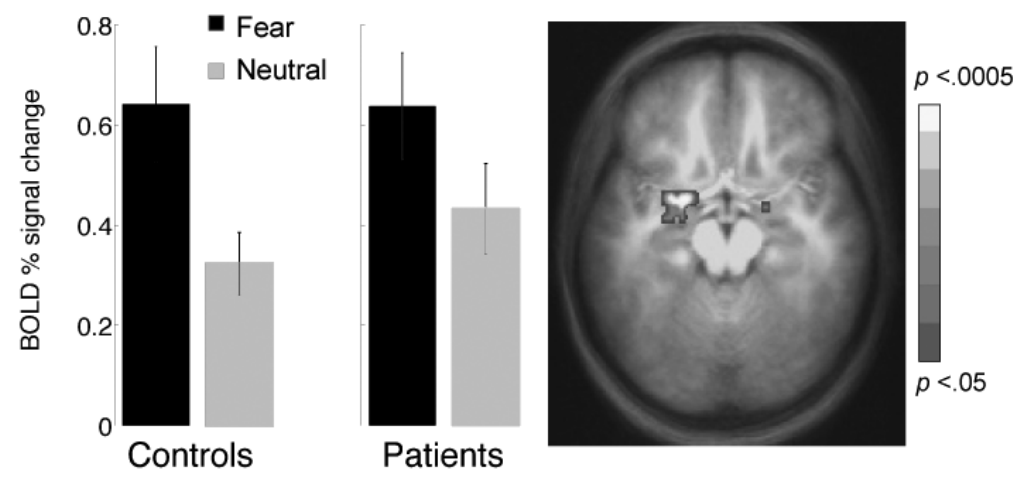

Figure 10.

Arousal modulation in amygdala activated at the onset of narrative imagery. ROI analyses of BOLD activity revealed that imagery of unpleasant script contents consistently elicited larger signal increases compared to neutral imagery in a similar pattern across patients $(\mathrm{N}=13)$ and controls $(\mathrm{N}=13)$. Error bars reflect within-subject $95 \%$ confidence intervals. 


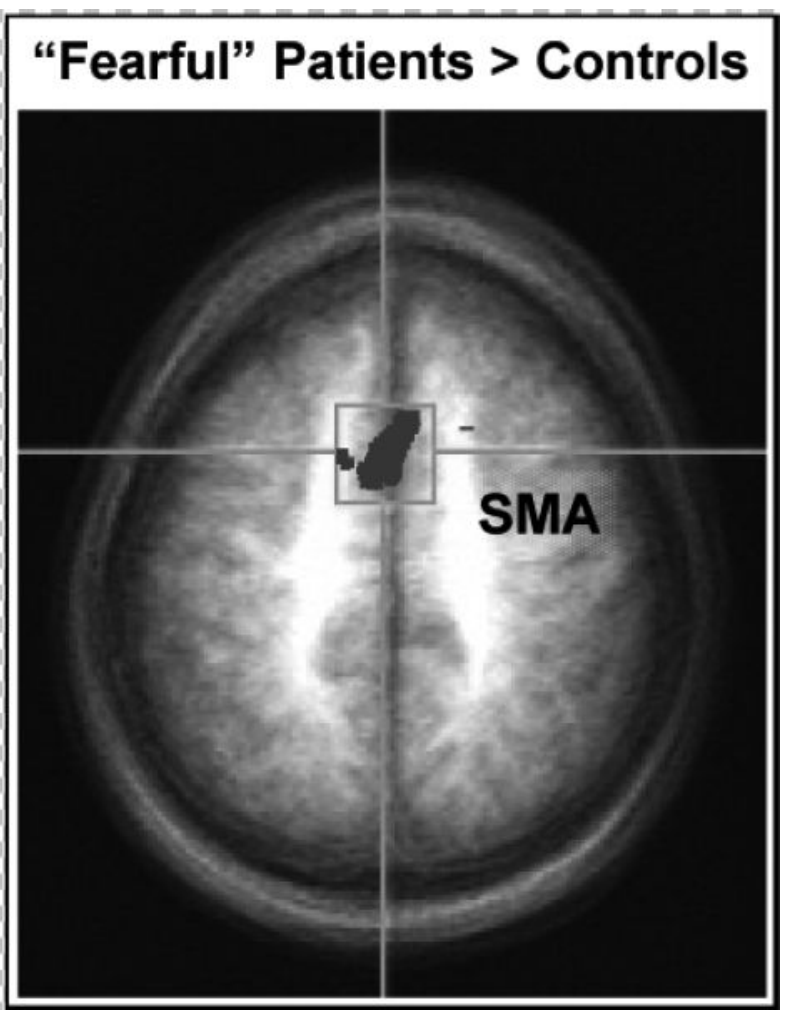

Figure 11.

Compared to control participants $(\mathrm{N}=13)$, "fearful" anxiety patients $(\mathrm{N}=7)$ were characterized by enhanced activation of supplementary motor cortex (SMA) during imagery of fearful contents $(p<.05$ corrected). 